\title{
An Introduction to \\ Finding Context
}

BY JOCELINE BOUCHER AND LAUREN E. SAHL

\section{PURPOSE OF ACTIVITY}

In this activity, students make a single measurement (chlorophyll) for the purpose of interpreting it in a regional, seasonal, and historical context. The activity introduces students to the vast amount of online oceanographic data, builds lab skills, and requires calculations that emphasize basic concepts and unit conversions.

\section{AUDIENCE}

The activity is one of several analytical labs in Introduction to Marine Science, a course for undergraduate Marine Science and Marine Biology majors at Maine Maritime Academy. The labs teach skills that students will use later on a research cruise. For this activity, students need to be familiar with the concept of density and have basic chemical safety skills.

\section{BACKGROUND}

We frequently ask students if their results "make sense." For those new to science, answering this question can be inherently daunting. Even advanced students may have trouble putting their research and lab results in context. Here we encourage students to contextually and quantitatively interpret their data.

We choose chlorophyll as the analyte for several reasons: chlorophyll data are available online; the chlorophyll extraction procedure is "hands-on" and easily mastered; and the extraction period provides time to obtain data and do calculations during lab. For our region, the Gulf of Maine Ocean Observing System's (GoMOOS) web site provides near-realtime data from buoys equipped with fluorometric sensors, and NOAA's CoastWatch web site provides access to recent surface chlorophyll concentrations derived from satellite observations of ocean color (Figure 1). Additionally, we access historical data at NOAA's online World Ocean Atlas. Comparing data among these sites requires unit conversions, another valuable introductory lesson. Lastly, the technique and web resources provide several "teaching moments" depending on the instructor's interests. These can include informal discussions of concentration factors, replication, solubility, fluorescence, light absorbance, principles of remote sensing, and more.

Chlorophyll analysis presents some difficulties, and instructors concerned about these may prefer to substitute another analyte such as salinity, dissolved oxygen, or a nutrient. One limitation of the method used here is the need to shorten the recommended 2 to 24 hour extraction period (Arar and Collins, 1997; Clesceri et al., 1998) to fit within a two- or three-hour lab. Other potential limitations are the need for a fume hood and seawater.

\section{RESEARCH QUESTION}

The emphasis in this activity is on context. The instructor needs to convey that context can be established even for a single data point such as measured here. The research question, then, begins with, "What is the concentration?" and leads to, "Is the datum oceanographically consistent?" Follow-up questions could include: Could the procedural modifications have contributed error? How does sampling location/depth/technique/time influence the result? Are direct comparisons of this measurement to other data valid? Students usually assume the online data are "better" than their measurements and this too could lead to further questions and discussion (Tomczak, 2006).

Joceline Boucher (jbouch@mma.edu) is Professor of Marine Chemistry, Corning School of Ocean Studies, Maine Maritime Academy, Castine, ME, USA. Lauren E. Sahl is Professor of Ocean Studies, Corning School of Ocean Studies, Maine Maritime Academy, Castine, ME, USA. 


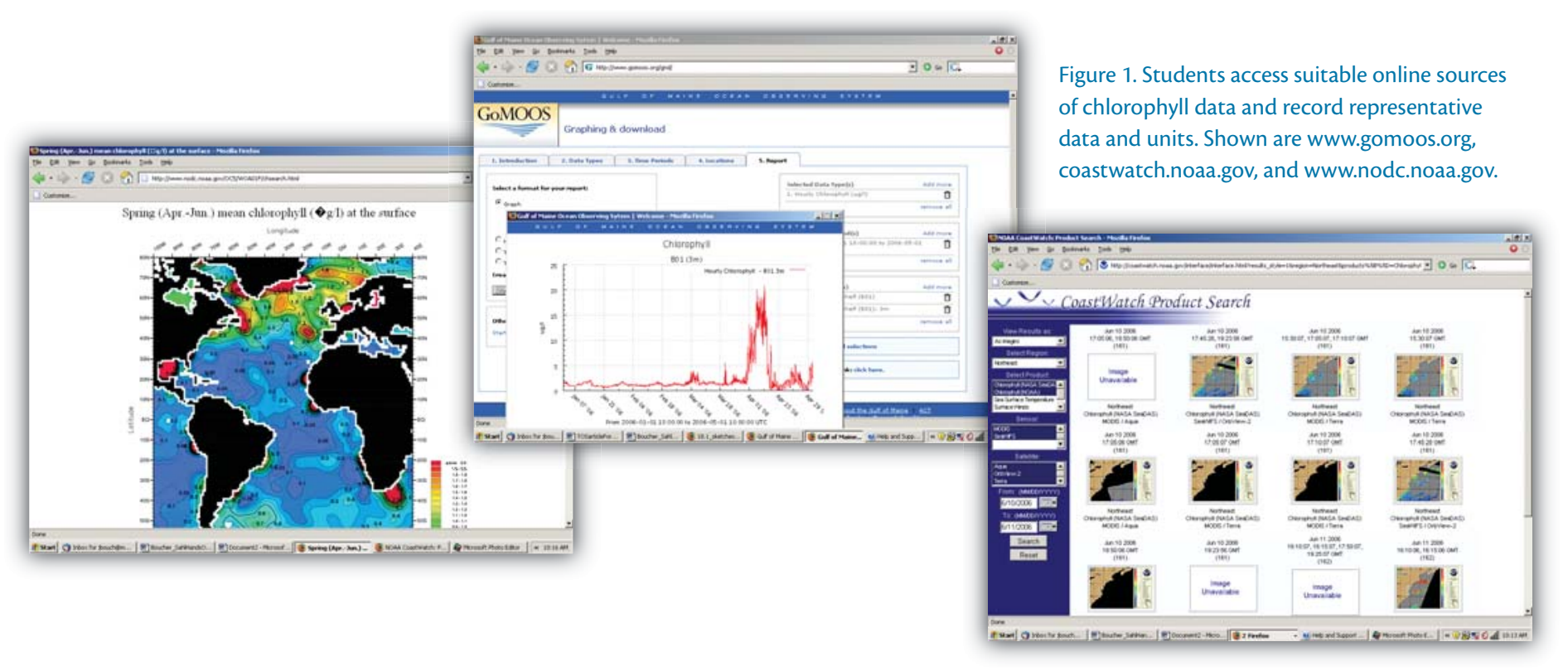

\section{APPROACH}

Students take turns preparing and filtering seawater to extract chlorophyll $a$, the primary pigment in marine phytoplankton. Chlorophyll $a$ is typically measured by spectrophotometric or fluorometric methods (e.g., Clesceri et al., 1991); fluorometric analysis is simpler, involves fewer calculations, and is used here. Our version largely follows the unacidified method of Arar and Collins (1997), substitutes weighing for pipetting, and replaces $90 \%$ acetone with the pure solvent. The use of a balance shortens preparation time and results in better student precision. Pure acetone is sometimes used to extract chlorophyll (e.g., Karl et al., 1990; Sun et al., 1991) and its use further simplifies student calculations.

During the extraction, students calculate sample volumes and concentration factors, then search online for chlorophyll data. Afterwards, they analyze the extractions with a fluorometer and finish the concentration calculation. Finally, they compare their measurements to data they have found online.

\section{MATERIALS}

\section{A. Per Class}

- fume hood

- fluorometer calibrated and configured to read in units of chlorophyll $a$ concentration

- balance (to at least $0.1 \mathrm{~g}$ )

- $47 \mathrm{~mm}$ diameter filter holder and chimney

- 1-2 L Erlenmeyer filtration flask to fit filter holder

- vacuum pump, tubing, and water trap

- $250 \mathrm{~mL}$ graduated cylinder

- several blunt-tip forceps

- several squirt bottles of acetone (technical grade or better). Fill bottles just prior to lab to prevent leaching of fluorescing compounds.

- several squirt bottles of filtered seawater

- Materials Data Safety Sheet (MSDS) for acetone (should be readily accessible)

- several tissue grinders or mortars and pestles

- centrifuge to fit test tubes (below)

- waste beaker
- test tube rack

- label tape and marker

- box of lab tissue

B. Per Student

- safety goggles

- polypropylene or glass screw-cap test tube (to hold $10 \mathrm{~mL}$ )

- $250 \mathrm{~mL}$ of surface seawater

- $47 \mathrm{~mm}$ diameter glass fiber filter (e.g. GF/F)

- disposable plastic pipet (3-5 mL)

- 2 fluorometer cuvettes

C. Per Student or Student Group

- computer with Internet access

- access to a refrigerator or ice chest

\section{ACTIVITY}

Ask each student to:

1. Record the mass of a glass fiber filter, and a labeled test tube with cap.

2. Filter enough seawater using the vacuum pump until color is just barely visible; record volume filtered (instructor may prefer to specify the volume). 
3. (In fume hood) Transfer filter to the tissue grinder, add a squirt of acetone, and grind filter until macerated.

4. Rinse the ground contents into the test tube, adjust acetone volume to roughly $10 \mathrm{~mL}$, cap, weigh, and record the mass of the capped test tube.

5. Set test tube in refrigerator for one hour.

6. Calculate the mass and volume of acetone in the test tube (density $\left._{\text {acetone }}=0.79 \mathrm{~g} \mathrm{~mL}^{-1}\right)$.

7. Determine the concentration factor of the extract $(\mathrm{CF}=$ Volume filtered $\div$ Volume of acetone).

8. Access suitable online sources of chlorophyll data. We use www. gomoos.org, coastwatch.noaa.gov, and www.nodc.noaa.gov (Figure 1). Record representative data and units.

9. Shake the test tube, then centrifuge until the supernatant is clear $(2-5$ minutes depending on centrifuge).

10. (In fume hood) Transfer supernatant into a cuvette using the disposable pipet.

11. Insert the cuvette in the fluorometer and record the sample's chlorophyll a concentration.

12. Fill a cuvette with acetone, then record its fluorescence as the "blank" value, in units of chlorophyll $a$ concentration.

13. Discard all wastes into the beaker (in fume hood).

14. Subtract the blank value from the sample reading. Using the concentration factor, determine the concentration of chlorophyll $a$ in the original seawater.

15. Convert the online and measured data to a common unit.

16. Quantitatively compare the measured data to the online data.

17. Summarize the comparisons in a paragraph.

\section{PRECAUTIONS}

- Room lights are dimmed or off during Steps 1-4 and 9-11 to prevent chlorophyll degradation, and are turned on during Steps 5-8.

- We use a Turner Designs 10-AU fluorometer, which requires a 45 -minute warm-up; to minimize acetone vapors, we place it in the fume hood. Alternatively, cuvettes can be capped with Parafilm ${ }^{\mathrm{TM}}$ and analyzed outside the hood.

- A weighing paper or pan will keep filters clean during weighing.

- The seawater bottle is rotated gently to suspend particles prior to sampling.

- Vacuum is less than 10-cm Hg (gauge) to prevent cell breakage (14 $\mathrm{kPa})$.

- The filtration chimney and graduated cylinder are rinsed with filtered seawater prior to each new use.

- Rinsing the forceps and pestle with acetone directly into the test tube minimizes sample loss following grinding.

- The cuvette is cleaned with acetone and a tissue as needed; students should avoid skin contact with acetone, or wear disposable gloves.

\section{GENERAL COMMENTS}

This activity requires two to three hours, depending on the number of students. It can be shortened or lengthened by changing the extraction time, or by omitting the grinding step (see modifications below). We use one balance, two filtration units, and two vacuum pumps for 16 students; with these, the class finishes Steps 1-4 in slightly under an hour. Students need about an hour to do the calculations and to access the online data in Steps 6-8 (we provide the URLs), and another hour to measure fluorescence and finish the calculations.

Preparation for the activity takes about an hour, not including getting seawater. Clean-up, which consists mostly of washing glassware, also takes an hour. Acetone wastes should be disposed of in accordance with the lab's chemical hygiene plan.

Students can be guided in their interpretations by starting at a global level. This information will help answer the most basic question, "Is my value high or low?" If the students and instructor examine global patterns of chlorophyll concentration together, this can be a teaching moment. The instructor can show the interdisciplinary nature of oceanography by emphasizing the link between seawater chemistry and ocean life. This connection sets the stage for understanding the reasons for temporal variability. Understanding the context of the measurements enables students to be actively involved in planning a research cruise later in the semester.

\section{POSSIBLE MODIFICATIONS}

Numerous analytical modifications to this activity are possible. Spectrophotometers could be used (e.g., Parsons et al., 1984) in place of fluorometers. Instructors without access to fume hoods could substitute ethanol for acetone (Sartory and Grobbelaar, 1984); those without vacuum pumps could substitute hand pumps or syringe filtration. Replacing glass fiber filters with membrane 
filters eliminates the need to centrifuge and simplifies transfer from the tissue grinder to the test tube. Most chlorophyll will extract without grinding; not grinding saves time and also eliminates the centrifuge step. Surface fresh waters or aquarium samples could substitute for seawaters, though relevant contextual data other than those suggested here will be needed.

Adding replication to the activity is a further possibility, if the class is small and time is available. Secondary chlorophyll standards (Turner Designs, 2006) could similarly be incorporated into the procedure. A field trip or short cruise to obtain seawater is another option.

This activity and others in the course are used to teach writing skills. We introduce just one section of the standard report format (introduction, methods, results, discussion, tables, and figures) per week; in our experience this is most effective in a first-year course. This lab lends itself to homework requiring students to write a discussion section. Readings prior to lab might also be assigned. NOAA's web site "The Living Ocean" (http://science.hq.nasa.gov/oceans/ living/index.html) is an excellent introduction to chlorophyll, ocean color, fluorescence, and remote sensing.

\section{REFERENCES}

Arar, E.J., and G.B. Collins. 1997. U.S. Environmental Protection Agency Method 445.0, In vitro determination of chlorophyll $a$ and pheophytin $a$ in marine and freshwater algae by fluorescence, revision 1.2: Cincinnati, Ohio, U.S. Environmental Protection Agency National Exposure Research Laboratory, Office of Research and Development. [Online] Available at: http:// www.epa.gov/nerlcwww/m445_0.pdf [last accessed August 12, 2006].

Clesceri, L.S., A.E. Greenberg, and A.D. Eaton, eds. 1998. Standard Methods for the Examination of
Water and Wastewater, $20^{\text {th }}$ ed. American Public Health Association, New York, NY, 1325 pp.

Karl, D.M., C.D. Winn, and D.V.W. Hebel. 1990. Hawaii Ocean Time-series Program Field and Laboratory Protocols. [Online] Available at: http://hahana.soest.hawaii.edu/hot/protocols/ protocols.html [last accessed August 12, 2006].

Parsons, T.R., C.M. Maita, and Y. Laili. 1984. A Manual of Chemical and Biological Methods for Seawater Analysis. Pergamon Press, New York, NY, 173 pp.

Sartory, D.P., and J.U. Grobbelaar. 1984. Extraction of chlorophyll $a$ from freshwater phytoplankton for spectrophotometric analysis. Hydrobiologia 114(3):177-187.

Sun, M., R.C. Aller, and C. Lee. 1991. Early diagenesis of chlorophyll- $a$ in Long Island Sound sediments: A measure of carbon flux and particle reworking. Journal of Marine Research 49(2):379-401.

Tomczak, T. 2006. How good are your data? Oceanography 19(2):148-150. [Online] Available at: http://www.tos.org/oceanography/issues/issue _archive/issue_pdfs/19_2/19.2_tomczak.pdf [last accessed August 12, 2006].

Turner Designs, Inc. 2006. RED Solid Secondary Standards for Chlorophyll a \& Rhodamine Analysis. [Online] Available at: http://www.turnerdesigns.com/t2/instruments/accessories/998_ 0056.html [last accessed August 12, 2006].

\section{ADDITIONAL ONLINE}

\section{RESOURCES}

If time is limited instructors may give students some of the information found at the suggested web sites.

\section{Global Context}

- A global map of sea surface chlorophyll a concentrations, based on satellite data. http://earthobservatory.nasa.gov/Newsroom/ NewImages/images.php3?img_id=16409

- Global maps of sea surface chlorophyll $a$ concentrations, by month, based on satellite data. http://marine.rutgers.edu/opp/Chlorophyll/ Chlorophyll1.html

- SeaWifs global and regional chlorophyll data based on satellite data. http://oceancolor.gsfc. nasa.gov/cgi/browse.pl

- Global maps of sea surface chlorophyll a concentrations, from the World Ocean Atlas/Database. The data include cruise and satellite data. http://www.nodc.noaa.gov/General/chloro.html

- General information on estuaries, including chlorophyll. http://omp.gso.uri.edu/doee/ science/physical/phys1.htm
Regional Context-Animations

- Gulf of Maine. http://www.cooa.unh.edu/ education/time_series.jsp

- U.S.A. coast north of Cape Hatteras. http:// www.po.gso.uri.edu/color/nec.html

- U.S.A. coast south of Cape Hatteras. http:// www.po.gso.uri.edu/color/sec.html

- Gulf of Mexico. http://imars.usf.edu/atlas/ images/CZCS_79.MPG

- Washington state. http://staff. washington.edu/ kae/ECOHAB/ECOHAB_ PNW.html\#Chlorophyll-a_

- Southern California bight. http://www.opl.ucsb. edu/satellite/animations/sb/sb06/sb_modis_ chlo_2006_a.gif

\section{Coastal Context}

Coastal ocean data within 25 miles of shore are given at the site below in table form. Estuarine data are not presented because the "data are not adequate for national reporting". This information could be used to show the need for chlorophyll measurements. See the linked technical note for a discussion of the data, including the use of water leaving radiance as a basis to estimate chlorophyll concentrations. http://www.heinzctr.org/ ecosystems/coastal/chlorophyll.shtml

HANDS-ON OCEANOGRAPHY We are interested in publishing peerreviewed laboratory hands-on exercises along with our regular education column. We expect the text plus graphics to fit on two to four published pages. Text should include the lab's theme, a list of supplies needed, approximate time needed to complete the lab, steps students (and teachers) need to proceed through, and any useful references. Please clearly indicate the academic level of the lab (e.g., undergraduate, graduate). Submit text and graphics for review to the Oceanography Editor, Ellen Kappel at ekappel@geo-prose.com. More information on Hands-On Oceanography and published exercises can be found at http://www.tos.org/hands-on. 